\title{
Implications of Plasma Renin Activity and Plasma Aldosterone Concentration in Critically Ill Patients with Septic Shock
}

\author{
Kyung Soo Chung ${ }^{1}$, Joo Han Song ${ }^{1}$, Won Jai Jung ${ }^{2}$, Young Sam Kim ${ }^{1}$, Se Kyu Kim ${ }^{1}$, Joon Chang ${ }^{1}$, and Moo Suk Park ${ }^{1}$ \\ 'Division of Pulmonology, Department of Internal Medicine, Institute of Chest Disease, Severance Hospital, Yonsei University College of Medicine, Seoul; ${ }^{2}$ Division of Pulmonology and \\ Critical Care Medicine, Department of Internal Medicine, Korea University Anam Hospital, Korea University College of Medicine, Seoul, Korea
}

Background: The renin-angiotensin-aldosterone system is closely associated with volume status and vascular tone in septic shock. The present study aimed to assess whether plasma renin activity (PRA) and plasma aldosterone concentration (PAC) measurements compared with conventional severity indicators are associated with mortality in patients with septic shock.

Methods: We evaluated 105 patients who were admitted for septic shock. Plasma levels of the biomarkers PRA and PAC, the PAC/PRA ratio, $\mathrm{C}$-reactive protein (CRP) level, and cortisol level on days 1,3 , and 7 were serially measured. During the intensive care unit stay, relevant clinical information and laboratory results were recorded.

Results: Patients were divided into two groups according to 28-day mortality: survivors $(n=59)$ and non-survivors $(n=46)$. The survivor group showed lower PRA, PAC, Acute Physiologic and Chronic Health Evaluation (APACHE) II score, and Sequential Organ Failure Assessment (SOFA) score than did the non-survivor group (all $P<0.05$ ). The SOFA score was positively correlated with PRA ( $r=0.373$, $P<0.001)$ and PAC $(r=0.316, P=0.001)$. According to receiver operating characteristic analysis, the areas under the curve of PRA and PAC to predict 28-day mortality were 0.69 ( $95 \%$ confidence interval $[\mathrm{Cl}], 0.58$ to $0.79 ; \mathrm{P}=0.001$ ) and $0.67(95 \% \mathrm{Cl}, 0.56$ to $0.77 ; \mathrm{P}=0.003$ ), respectively, similar to the APACHE II scores and SOFA scores. In particular, the group with PRA value $\geq 3.5 \mathrm{ng} \mathrm{ml}^{-1} \mathrm{~h}^{-1}$ on day 1 showed significantly greater mortality than did the group with PRA value $<3.5 \mathrm{ng} \mathrm{ml}^{-1} \mathrm{~h}^{-1}$ (log-rank test, $\mathrm{P}<0.001$ ). According to multivariate analysis, SOFA score (hazard ratio, $1.11 ; 95 \% \mathrm{Cl}, 1.01$ to 1.22 ), PRA value $\geq 3.5 \mathrm{ng} \mathrm{ml}^{-1} \mathrm{~h}^{-1}$ (hazard ratio, 3.25; $95 \% \mathrm{Cl}, 1.60$ to 6.60 ), previous history of cancer (hazard ratio, $3.44 ; 95 \% \mathrm{Cl}, 1.72$ to 6.90 ), and coronary arterial occlusive disease (hazard ratio, $2.99 ; 95 \% \mathrm{Cl}, 1.26$ to 7.08) were predictors of 28-day mortality.

Conclusions: Elevated PRA is a useful biomarker to stratify the risk of critically ill patients with septic shock and is a prognostic predictor of 28-day mortality.

Key Words: aldosterone; mortality; renin; shock, septic.

\section{Introduction}

High morbidity and mortality from severe sepsis and septic shock is still an unresolved challenging [1,2]. Sepsisinduced tissue hypoperfusion and organ dysfunction result from vasodilation, decreased systemic vascular resistance, and increased microvascular leakage [3]. Hypotension triggers a complex neurohumoral response during severe sepsis to maintain blood pressure homeostasis, resulting in increased sympathetic responses and hypothalamic-pituitary-adre-

\footnotetext{
Received on February 9, 2017 Revised on April 15, 2017 Accepted on April 15, 2017

Correspondence to: Moo Suk Park, Division of Pulmonology, Department of Internal Medicine, Institute of Chest Disease, Severance Hospital, Yonsei University College of Medicine, 50 Yonsei-ro, Seodaemun-gu, Seoul 03722, Korea Tel: +82-2-2228-1955, Fax: +82-2-393-6884, E-mail: PMS70@yuhs.ac

*No potential conflict of interest relevant to this article was reported.
} 
nal axis stimulation [4]. The lack of this response in critically ill patients is related to a poor prognosis $[5,6]$.

To preserving blood pressure homeostasis, the reninangiotensin-aldosterone system (RAAS) is required. By loss of blood volume or a drop in blood pressure, RAAS induces hormonal activation sequentially with renin-angiotensin I-angiotensin II-aldosterone. This sophisticated system controls microvascular, blood pressure, and organ function [7], as well as inflammatory responses. The dissociation of plasma renin activity (PRA) and aldosterone production, namely hyperreninemic hypoaldosteronism, has been observed in approximately $20 \%-30 \%$ of critically ill patients, increasing the development of acute renal failure, other organ dysfunction, and death [8].

Table 1. Baseline characteristics according to 28-day mortality

\begin{tabular}{|c|c|c|c|}
\hline Characteristic & Non-survivors $(n=46[43.8])$ & Survivors $(n=59[56.2])$ & P-value \\
\hline Age (yr) & $65.0(54.0-73.3)$ & $65.0(56.0-74.0)$ & 0.824 \\
\hline Male sex & $28(60.9)$ & $37(62.7)$ & 1.000 \\
\hline APACHE II score & $26.0(23.8-31.0)$ & $22.0(18.0-28.0)$ & 0.001 \\
\hline SOFA score & $9.0(7.0-12.3)$ & $7.0(4.0-10.0)$ & 0.001 \\
\hline \multicolumn{4}{|l|}{ Comorbidity } \\
\hline CAOD & $7(15.2)$ & $2(3.4)$ & 0.040 \\
\hline Hypertension & $13(28.3)$ & $28(47.5)$ & 0.069 \\
\hline Diabetes & $10(21.7)$ & $21(35.6)$ & 0.137 \\
\hline Heart failure & $6(13.0)$ & $6(10.2)$ & 0.760 \\
\hline Chronic lung disease & $7(15.2)$ & $11(18.6)$ & 0.795 \\
\hline Chronic renal disease & $6(13.0)$ & $6(10.2)$ & 0.760 \\
\hline Chronic liver disease & $12(26.1)$ & $9(15.3)$ & 0.220 \\
\hline Cancer & $35(76.1)$ & $24(40.7)$ & $<0.001$ \\
\hline Primary site of infection & & & 0.814 \\
\hline Pulmonary & $34(73.9)$ & 41 (69.5) & \\
\hline Pancreato-biliary & $1(2.2)$ & $5(8.5)$ & \\
\hline Liver & $4(8.7)$ & $3(5.1)$ & \\
\hline Gl tract & $2(4.3)$ & $3(5.1)$ & \\
\hline Soft tissue and bone & $1(2.2)$ & $1(1.7)$ & \\
\hline Brain and CSF & 0 & $1(1.7)$ & \\
\hline Kidney & $1(2.2)$ & $1(1.7)$ & \\
\hline Urogenital & $1(2.2)$ & $3(5.1)$ & \\
\hline Miscellaneous & $2(4.3)$ & $1(1.7)$ & \\
\hline Positive blood culture & $17(37.0)$ & $18(30.5)$ & 0.535 \\
\hline Acute renal failure & & & 0.489 \\
\hline At risk & $11(23.9)$ & $15(25.4)$ & \\
\hline Injury & $9(19.6)$ & $14(23.7)$ & \\
\hline Failure & $3(6.5)$ & $8(13.6)$ & \\
\hline Chronic renal disease acute exacerbation, & $6(13.0)$ & $6(10.2)$ & 0.760 \\
\hline Steroid use within 7 days & $29(63.0)$ & $24(40.7)$ & 0.031 \\
\hline No. of CRRT applied within 7 days & $18(39.1)$ & $10(16.9)$ & $<0.001$ \\
\hline
\end{tabular}

Values are presented as number (\%) or median (interquartile range).

APACHE: Acute Physiology and Chronic Health Evaluation; SOFA: Sequential Organ Failure Assessment; CAOD: coronary arterial occlusive disorder; CSF: cerebrospinal fluid; CRRT: continuous renal replacement therapy. 
Plasma aldosterone concentrations (PACs) are useful biomarker to detect septic shock patients with a high risk of renal dysfunction [8].

However, little is known regarding the usefulness of PRA and PAC measurements in prediction of mortality or relations with mortality in patients with septic shock. We hypothesized that prolonged septic shock increases PRA and PACs, resulting in increased inflammatory activity, organ failure, and mortality. In this study, we examined whether PRA and PAC measurement compared with conventional severity indicators are associated with 28-day mortality in patients with septic shock.

\section{Materials and Methods}

\section{1) Study design and setting}

This study was a prospective blood sampling and retrospective data analysis of a cohort of patients admitted to the medical intensive care unit (ICU) from August 2008 to January 2009 . We enrolled 140 patients aged older than 19 years who had been admitted to the ICU with septic shock from August 2008 to January 2009. All of the patients met the following criteria for septic shock, as established by the International Sepsis Definitions Conference [9]: (1) clinical diagnosis of septic shock made within the past 48 hours with a documented bacterial infection and (2) at least two of the following: fever (body temperature, $\left.>38^{\circ} \mathrm{C}\right)$ or hypothermia $\left(<36^{\circ} \mathrm{C}\right)$, heart rate $>90$ beats $\min ^{-1}$, respiratory rate $>20$ breaths $\min ^{-1}$, white blood cell count $>12,000$ cells $\mathrm{mm}^{-3}$ or $<4,000$ cells $\mathrm{mm}^{-3}$, or $>10 \%$ immature (band) forms. Patients also had to meet the additional following criteria for septic shock: the presence of at least two signs of organ dysfunction (metabolic acidosis, arterial hypoxemia $\left[\mathrm{PaO}_{2} / \mathrm{FiO}_{2}\right.$ ratio $\left.<250\right]$, oliguria $\left[<30 \mathrm{ml} \mathrm{kg}^{-1}\right.$ for 3 hours], intravascular disseminated coagulopathy, or an abrupt change in mental status); and persistent hypotension with systolic blood pressure of $<90 \mathrm{mmHg}$ for at least 1 hour, despite adequate fluid replacement (assessed by a central venous pressure $>8 \mathrm{mmHg}$ ) and continuous administration of inotropic or vasopressor support [9].

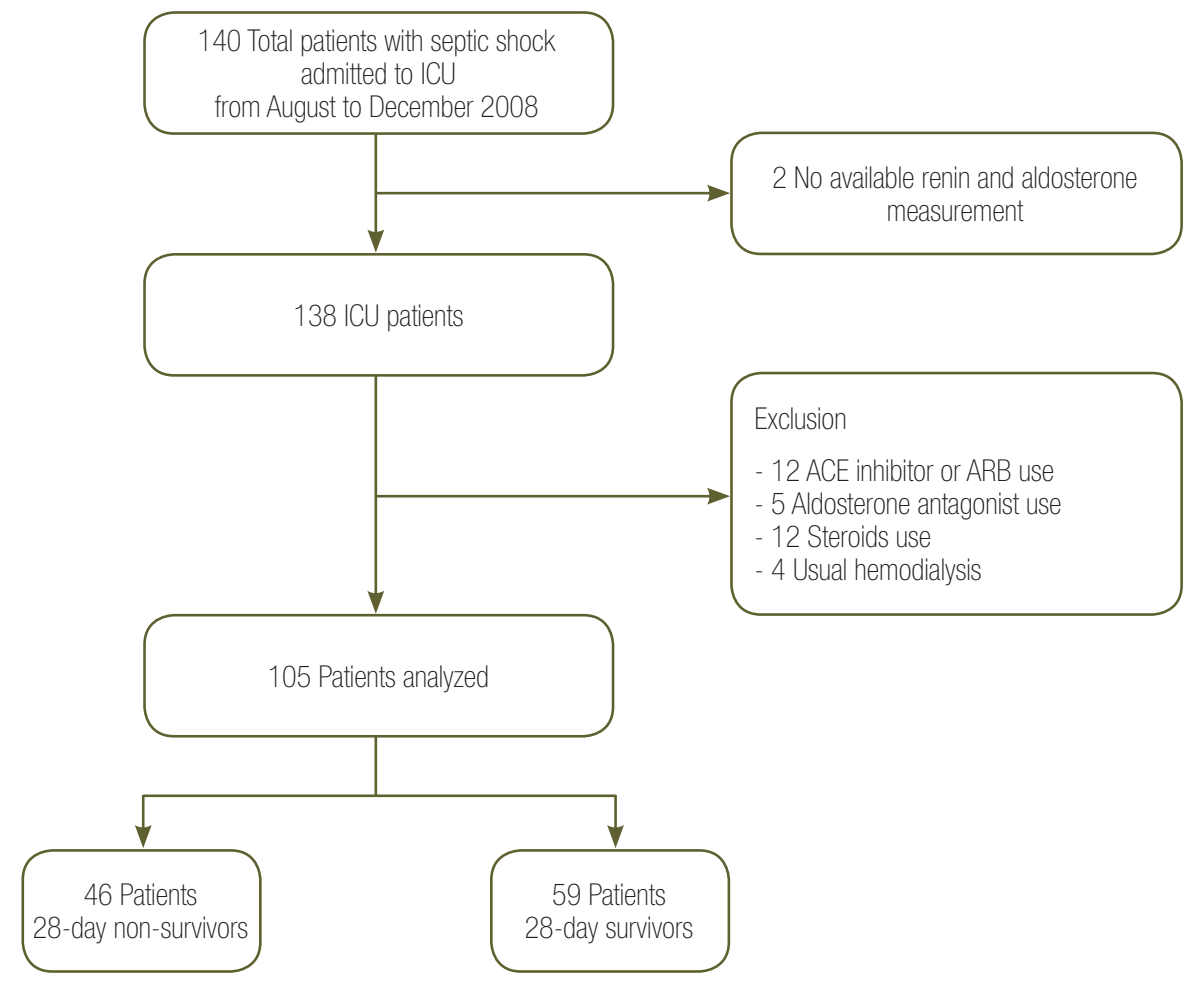

Figure 1. Flow chart of inclusion and exclusion of patients in the study. A total of 140 patients were enrolled between August and December 2008, and 105 patients were included in the analysis. Patients without available renin and aldosterone measurements ( $\mathrm{n}$ $=2$ ), those using an angiotensinconverting enzyme (ACE) inhibitor or angiotensin receptor blocker (ARB) $(n=12)$, those using an aldosterone antagonist $(n=5)$, those using steroids $(\geq 15 \mathrm{mg} / \mathrm{d})(\mathrm{n}=12)$, and those who had previous usual hemodialysis $(n=4)$ within 7 days were excluded. ICU: intensive care unit. 
We excluded two patients without PAC or PRA measurements. We also excluded 33 patients who had previously taken angiotensin-converting enzyme inhibitors or angiotensin receptor blockers $(\mathrm{n}=12)$, who previously took aldosterone antagonists $(\mathrm{n}=5)$, who had a history of steroid usage ( $n=12)$, and who had previously used hemodialysis $(n=4)$. A total of 105 patients were included in the study. Demographic, clinical, and biochemical data at the time of ICU admission were recorded. Baseline characteristics are shown in Table 1 and Figure 1.

\section{2) Data collection}

To assess the severity of illness and prognosis of the underlying disease, the Acute Physiology and Chronic Health Evaluation (APACHE) II score and Sequential Organ Failure Assessment (SOFA) score were evaluated at the initial time of ICU admission. The SOFA score was also recorded on days 1,3 , and 7 . Data of the following parameters were also collected: age, sex, total fluid input and output, serum creatinine levels, arterial blood gas analysis, and serum electrolytes. Additionally, patients were assessed with respect to their need for mechanical ventilation, ventilator-free days, and/or renal replacement therapy. All of the patients were evaluated over their entire ICU stay, and ICU-free days and outcomes were recorded. The definitions of ventilator free-days and ICU free-days are as follows:

Ventilator free-days $=$ number of days from day 1 to day 28 on which a patient breathed without assistance (if the period of unassisted breathing lasted at least 48 consecutive hours)

ICU free-days $=$ number of days from day 1 to day 28 on which a survived patient is not in ICU

\section{3) Plasma biomarker sampling}

Blood samples were collected with the patient in the supine position in the early morning. On the day of sampling, blood samples were immediately sent to a laboratory for measuring biomarkers, such as PACs (by radioimmunoassay; normal range, 29.9 to $158.8 \mathrm{ng} \mathrm{dl}^{-1}$; Cobra II gamma counter, Hewlett-Packard, Meriden City, KS, USA),
PRA (by radioimmunoassay; normal range, 0.15 to 2.23 ng $\mathrm{ml}^{-1} \mathrm{~h}^{-1}$; Cobra II gamma counter, Hewlett-Packard), plasma cortisol levels (by comparative binding immunoenzymatic assay; normal range, 6.7 to $22.6 \mathrm{pg} \mathrm{ml}^{-1}$; UNICEL DXI 800, Beckman Coulter Inc., Brea, CA, USA), and C-reactive protein (CRP) levels (by immunoturbidimetry; normal range, 0 to $8.0 \mathrm{mg} \mathrm{L}^{-1}$; Hitachi 7600 , Sekisui, Japan). Serial PACs, PRA, the PAC/PRA ratio, cortisol levels, and CRP levels were measured on days 1, 3, and 7 to analyze changes over time. Based on the previous study, the definition of hyperreninemic hypoaldosteronism was defined when PAC/PRA ratio was less than 2 [8].

\section{4) Statistical analyses}

Continuous variables are presented as the mean \pm standard deviation or median (interquartile range) and categorical variables as number (percentage) of the total sample. Baseline characteristics of the groups were compared using the $\chi^{2}$ test or Fisher exact test for categorical variables. And nonnormally distributed variables were compared using the Mann-Whitney U-test, and normally distributed variables using Student t-test when analyzing continuous variables. Pearson correlation was performed to investigate the relationships between SOFA scores and PRA or PACs. We evaluated 28-day all-cause mortality as the study endpoint. We conducted receiver operating characteristic (ROC) analysis to compare the predictive accuracy of PRA or PACs and APACHE II scores or SOFA scores. The area under the curve (AUC) was calculated. The Youden index was used to determine the optimal cutoff value of PRA or PACs for predicting 28day mortality. Survival curves were prepared using the Kaplan-Meier method, and comparisons were made using the log-rank test. Prognostic variables for mortality were analyzed using the univariate Cox proportional hazards model, and variables with P-values $<0.1$ were used in the multivariate Cox proportional hazard model with backward selection. Results of univariate and multivariate Cox regression analyses are presented as hazard ratios and 95\% confidence intervals (CIs). Differences were considered statistically significant at $\mathrm{P}<0.05$ (two-tailed). Sta- 
Table 2. Clinical and biological characteristics according to 28-day mortality

\begin{tabular}{|c|c|c|c|}
\hline Variable & Non-survivor $(\mathrm{n}=46[43.8])$ & Survivor $(n=59[56.2])$ & P-value \\
\hline Mechanical ventilation used & $43(93.5)$ & $49(83.1)$ & 0.140 \\
\hline Heart rate (beats min $^{-1}$ ) & $120.0(90.5-136.5)$ & $105.0(81.0-126.0)$ & 0.036 \\
\hline Mean arterial pressure (mmHg) & $69.2(62.8-92.6)$ & $79.0(65.7-99.3)$ & 0.129 \\
\hline $\mathrm{pH}$ & $7.4(7.3-7.5)$ & $7.4(7.3-7.5)$ & 0.395 \\
\hline $\mathrm{PaCO}_{2}(\mathrm{mmHg})$ & $35.7(29.5-41.0)$ & $32.2(27.4-36.6)$ & 0.320 \\
\hline P/F ratio & $197.7(150.7-257.9)$ & $264.6(180.5-365.5)$ & 0.002 \\
\hline PEEP $\left(\mathrm{cmH}_{2} \mathrm{O}\right)$ & $10.0(8.0-12.0)$ & $10.0(6.0-12.0)$ & 0.679 \\
\hline Platelet $\left(10^{3} / \mu \mathrm{l}\right)$ & $128.0(52.5-227.8)$ & $159(76.0-314.0)$ & 0.278 \\
\hline Serum potassium $\left(\mathrm{mmol} \mathrm{L}^{-1}\right)$ & $3.8(3.4-4.6)$ & $3.7(3.3-4.1)$ & 0.301 \\
\hline Serum sodium (mmol L $\left.\mathrm{L}^{-1}\right)$ & $137.0(134.8-144.0)$ & $138.0(134.0-142.0)$ & 0.279 \\
\hline Blood urea nitrogen (mg $\mathrm{dl}^{-1}$ ) & $24.7(16.2-40.1)$ & $25.6(15.6-41.0)$ & 0.853 \\
\hline Serum creatinine ( $\left.\mu \mathrm{mol} \mathrm{L}^{-1}\right)$ & $1.3(0.7-1.9)$ & $1.2(0.9-2.2)$ & 0.760 \\
\hline Ejection fraction (\%) & $66.0(54.0-70.0)$ & $66.0(60.0-70.0)$ & 0.551 \\
\hline Net fluid balance at 1 days $(\mathrm{L})$ & $2.0(0.5-3.4)$ & $1.0(0.2-2.3)$ & 0.022 \\
\hline \multicolumn{4}{|l|}{ Blood Biomarkers } \\
\hline $\mathrm{CRP}\left(m g \mathrm{~L}^{-1}\right)$ & $14.3(5.8-28.7)$ & $13.8(8.3-23.3)$ & 0.578 \\
\hline Cortisol $\left(p g \mathrm{ml}^{-1}\right)$ & $23.8(15.2-46.0)$ & $25.0(15.8-45.3)$ & 0.210 \\
\hline PRA $\left(n g m^{-1} h^{-1}\right)$ & $8.7(3.2-23.4)$ & $2.4(0.7-7.9)$ & 0.003 \\
\hline PAC $\left(\right.$ ng d $\left.^{-1}\right)$ & $125.9(37.0-255.9)$ & $53.8(23.0-135.7)$ & 0.008 \\
\hline PAC/PRA ratio & $1.2(0.6-3.0)$ & $1.9(0.7-5.9)$ & 0.581 \\
\hline $\mathrm{PAC} / \mathrm{PRA}<2$ & $23(50.0)$ & $35(59.3)$ & 0.429 \\
\hline
\end{tabular}

Values are presented as number (\%) or median (interquartile range).

$\mathrm{P} / \mathrm{F}: \mathrm{PaO}_{2} / \mathrm{FIO}_{2}$; PEEP: positive end-expiratory pressure; CRP: C-reactive protein; PRA: plasma renin activity; PAC: plasma aldosterone concentration.

tistical analyses were performed using the SPSS software package version 18.0 (SPSS Inc., Chicago, IL, USA).

\section{5) Ethics statement}

The protocol was approved by our institutional review board (No. 4-2008-0099). Written informed consent was obtained from the patients or their next of kin.

\section{Results}

\section{1) Baseline characteristics of the study population}

A total of 105 patients with septic shock were enrolled. There were 65 (61.9\%) men and 40 (38.1\%) women. The mean age was 63.6 years (range, 55 to 74 years). The 28 day mortality was $43.8 \%(n=46)$ and these patients were classified as non-survivors. The remaining patients were classified as survivors. Table 1 shows the comparison of demographics and clinical parameters on day 1 between non-survivors and survivors. Age, sex, primary infection site, the rate of positive blood culture, the comorbidities are similar in both groups. However, the survivor group showed lower APACHE II scores $(\mathrm{P}=0.001)$ and SOFA scores $(\mathrm{P}=0.001)$, and a much more prevalent history of coronary arterial occlusive disease or cancer than did the non-survivor group. In terms of critical care needs, patients in the non-survivor group had less ventilator-free days ( $\mathrm{P}<0.001)$ and ICU-free days $(\mathrm{P}<0.001)$, and required a higher number of steroid use and continuous renal replacement therapy applications within 7 days after admission than did those in the non-survivor group. The non-survivor group showed a higher heart rate $(\mathrm{P}=0.036)$ 

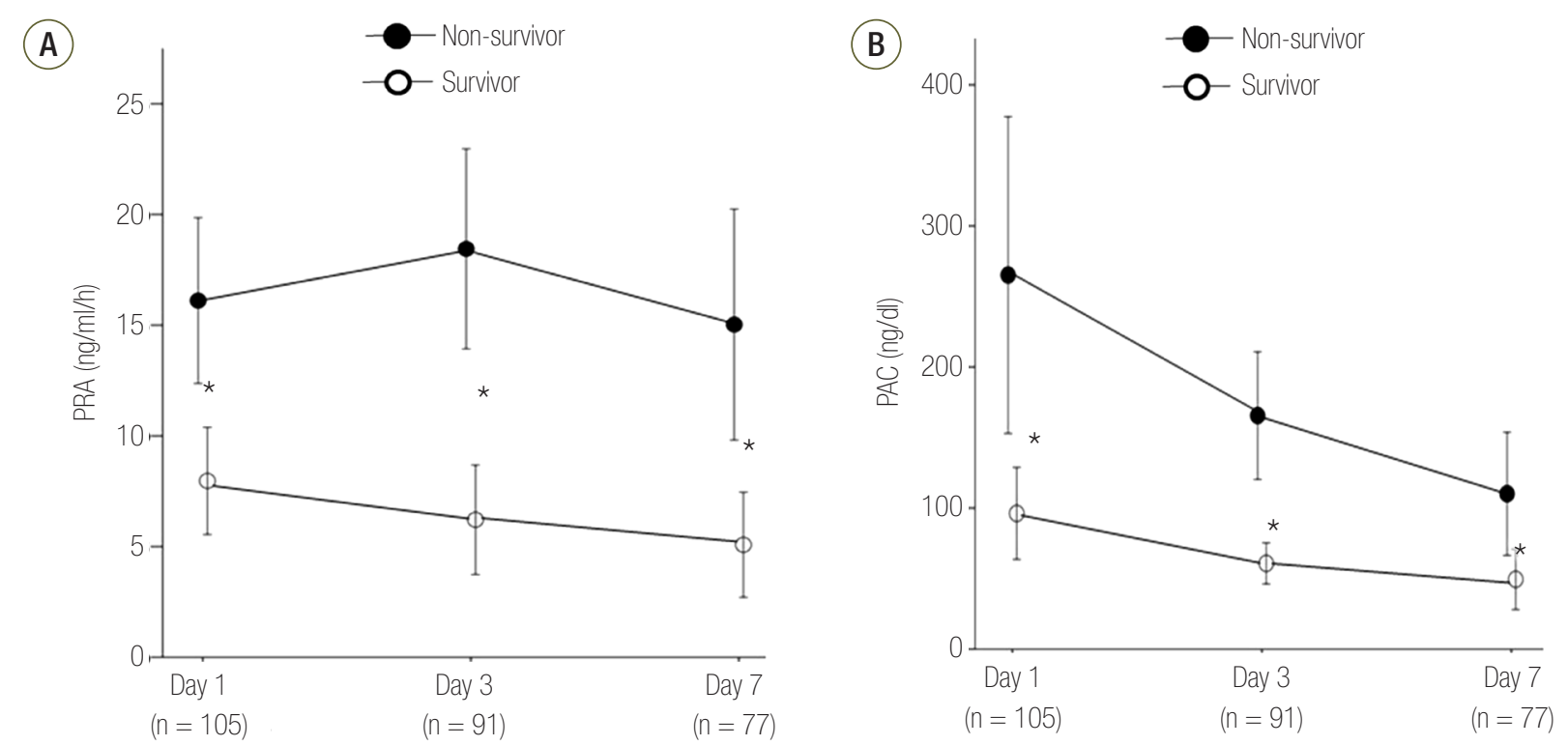

Figure 2. Time courses of PRA and PACs in non-survivors versus survivors. Levels of PRA (A) and PACs (B) were measured on days 1,3 , and 7 after admission. The circles and bars indicate the mean values and SEM, respectively. Significant differences between nonsurvivors and survivors are indicated by an asterisk ( ${ }^{*} P<0.05$, survivors versus non-survivors on each day). PRA: plasma renin activity; PAC: plasma aldosterone concentration; SEM: standard error of the mean. and net fluid balance on day $1(\mathrm{P}=0.022)$, but a lower $\mathrm{PaO}_{2} / \mathrm{FiO}_{2}$ ratio $(\mathrm{P}=0.002)$, than did the survivor group. The survivor group showed significantly lower PRA (P = $0.003)$ and PACs $(P=0.008)$ than did the non-survivor group. However, there were no significant differences in other blood biomarkers, such as CRP levels, cortisol levels, and the PAC/PRA ratio, between the non-survivor and survivor groups (Tables 1 and 2).

\section{2) Time course of PRA and PACs during the first 7 ICU days in the non-survivor and survivor groups}

The time course of PRA in he survivors and non-survivors was as follows. PRA and PACs in the survivors were significantly lower than in the non-survivors on days 1 , 3, and 7 (Figure 2, Supplementary Table 1). PACs were significantly lower in the survivor group than in the nonsurvivor group on days $1(\mathrm{P}=0.008), 3(\mathrm{P}=0.001)$, and $7(\mathrm{P}=0.012)$. CRP levels, cortisol levels, and the PAC/ PRA ratio were not different between the non-survivor and survivor groups on day 1, 3, and 7 (Supplementary Table 1). When serial PAC, PRA, cortisol, and CRP level were measured, PAC and PRA level were consistently lower in the surviving group, but CRP and cortisol level

\section{3) Correlations between PRA or PACs and the APACHE II score and SOFA score}

PRA was positively correlated with the APACHE II score $(\mathrm{r}=0.230, \mathrm{P}=0.018)$ and the SOFA score $(\mathrm{r}=$ $0.373, \mathrm{P}<0.001$ ) (Figure $3 \mathrm{~A}$ and $\mathrm{B}$ ). PACs were only positively correlated with the SOFA score $(r=0.316, \mathrm{P}$ $=0.001$ ) (Figure 3C and D). However, both biomarkers showed weak positive correlation.

\section{4) Risk analysis for 28-day mortality}

The areas under the ROC curve for PRA and PAC values on day 1 were $0.69(95 \% \mathrm{CI}, 0.58$ to $0.79 ; \mathrm{P}=0.001)$ and $0.67(95 \% \mathrm{CI}, 0.56$ to $0.77 ; \mathrm{P}=0.003)$, respectively. These values were similar to the APACHE II scores (AUC, $0.68 ; 95 \% \mathrm{CI}, 0.58$ to $0.78 ; \mathrm{P}=0.001)$ and SOFA scores (AUC, 0.67; 95\% CI, 0.57 to 0.77; $\mathrm{P}=0.003$ ) (Figure 4). Therefore, based on the maximal value of the Youden index $(\mathrm{J}=0.25)$, the most discriminatory markers were PRA with a cutoff of $3.5 \mathrm{ng} \mathrm{ml}^{-1} \mathrm{~h}^{-1}$ (sensitivity of $76.1 \%$ and specificity of $64.4 \%$ ) and PAC with a cutoff of 112 $n g \mathrm{dl}^{-1}$ (sensitivity of $58.7 \%$ and specificity of $71.2 \%$ ) for 

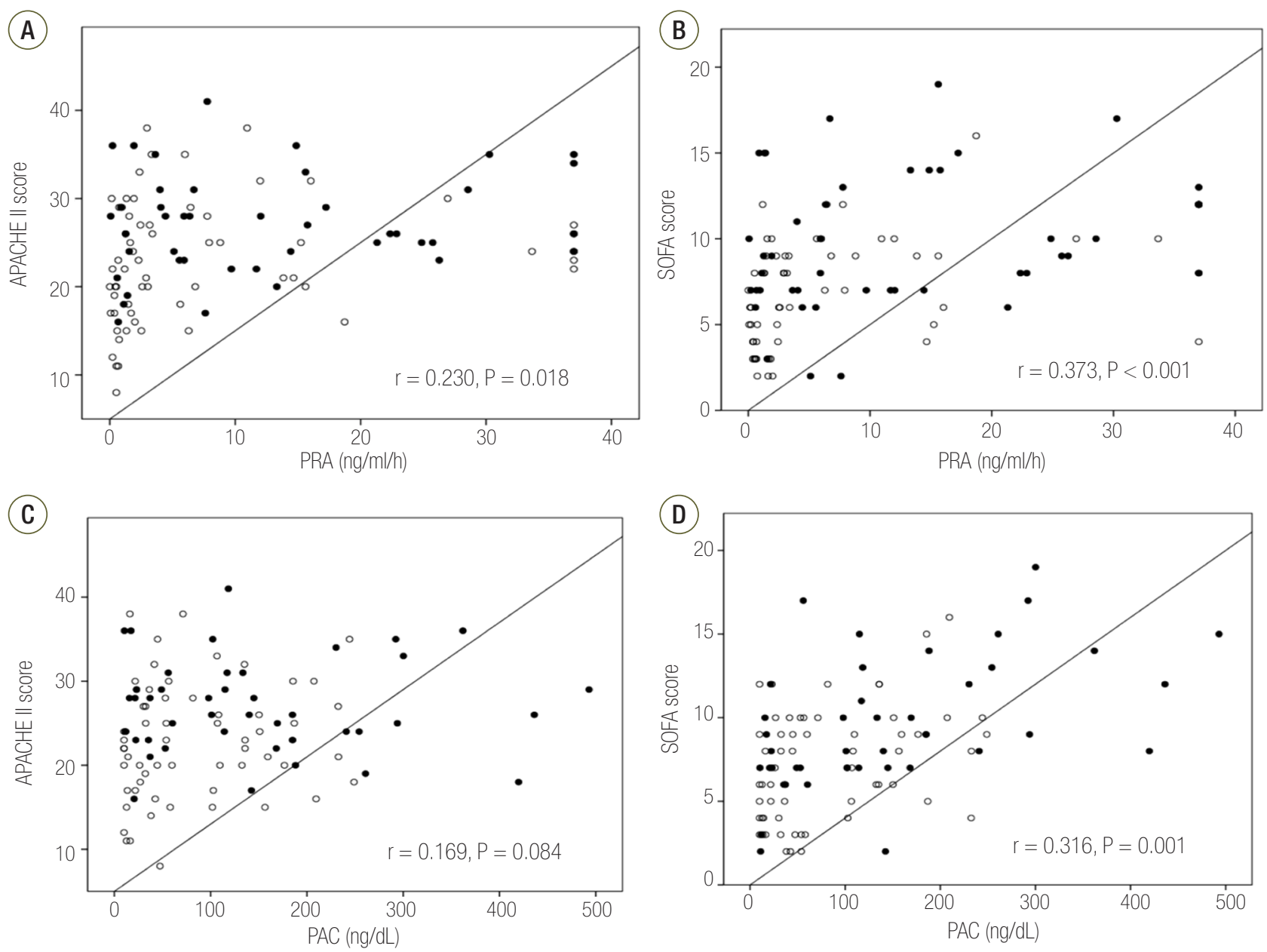

Figure 3. Correlations between PRA or PAC, SOFA score, and APACHE II score on day 1. The PRA levels correlated with better with APACHE II score (A) or SOFA score (B) than the PAC levels $(C, D)$ although there were weak correlations. The open circles indicate survivors, and the solid circles indicate non-survivors. APACHE: Acute Physiologic and Chronic Health Evaluation; PRA: plasma renin activity; SOFA: Sequential Organ Failure Assessment; PAC: plasma aldosterone concentration.

predicting 28-day mortality. Kaplan-Meier survival analysis showed that the 28-day mortality of patients with PRA values $\geq 3.5 \mathrm{ng} \mathrm{ml}^{-1} \mathrm{~h}^{-1}(\mathrm{n}=49)$ was higher than that of patients with PRA values $<3.5 \mathrm{ng} \mathrm{ml}^{-1} \mathrm{~h}^{-1}(\mathrm{n}=56)$ (log-rank test, $\mathrm{P}<0.001$, Figure 5). Using Cox regression analysis, PRA and PACs, as well as several other clinical characteristics to predict 28-day mortality, were evaluated (Table 3). After adjusting for confounding factors, the SOFA score (hazard ratio, $1.11 ; 95 \% \mathrm{CI}, 1.01$ to 1.22 ), PRA values $\geq 3.5 \mathrm{ng} \mathrm{ml}^{-1} \mathrm{~h}^{-1}$ (hazard ratio, 3.25; 95\% CI, 1.60 to 6.60 ), previous history of cancer (hazard ratio, 3.44; 95\% CI, 1.72 to 6.90) and coronary arterial occlusive disease (hazard ratio, 2.99 ; $95 \% \mathrm{CI}, 1.26$ to 7.08 ) were independently as- sociated with 28-day mortality.

\section{Discussion}

In the current study, we assessed clinical parameters, including serial serum PRA and PACs of septic shock patients on days 1, 3, and 7 after admission to ICU in a single-center cohort. The main findings of this study were as follows: (1) 28-day survivors showed lower PRA and PAC values than did 28-day non-survivors; (2) PRA and PACs were positively correlated with severity scores; and (3) in particular, patients with septic shock with PRA 
values $\geq 3.5 \mathrm{ng} \mathrm{ml}^{-1} \mathrm{~h}^{-1}$ on day 1 were related to 28 -day mortality.

APACHE II score or SOFA score are used as a good indicator of the severity stratification or prognosis predication of patients with sepsis in the ICU. In our study, PRA and PACs were positively correlated with the SOFA

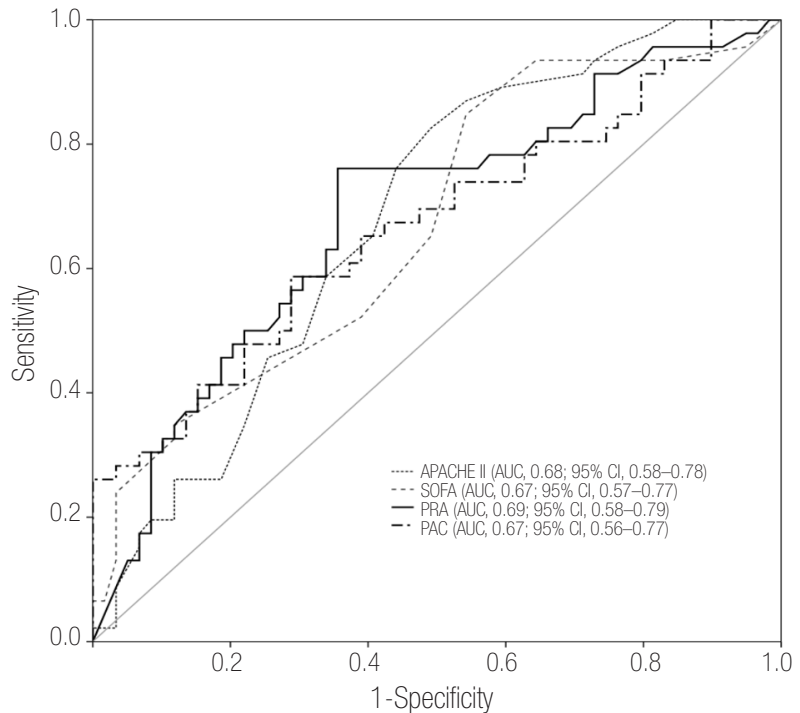

Figure 4. Receiver operating characteristic curves for PRA and PAC on day 1 for predicting 28-day mortality. The prognostic accuracy of PRA and PAC was not inferior to that of the APACHE II and SOFA scores. APACHE: Acute Physiologic and Chronic Health Evaluation; AUC: area under the curve; $\mathrm{Cl}$ : confidence interval; SOFA: Sequential Organ Failure Assessment; PRA: plasma renin activity; PAC: plasma aldosterone concentration. score on days 1, 3, and 7. Their prognostic accuracy was similar to that of SOFA scores for mortality. PRA values $\geq 3.5 \mathrm{ng} \mathrm{ml}^{-1} h^{-1}$ on day 1 was identified as an independent factor associated with 28-day mortality, even after adjusting for other parameters and severity scores (APACHE II and SOFA score). Although a single biomarker cannot substitute a composite indicator of severity such as APACHE II score or SOFA score, our findings may help to understand the pathophysiology in septic shock. And these results could be explained as follows. Over the

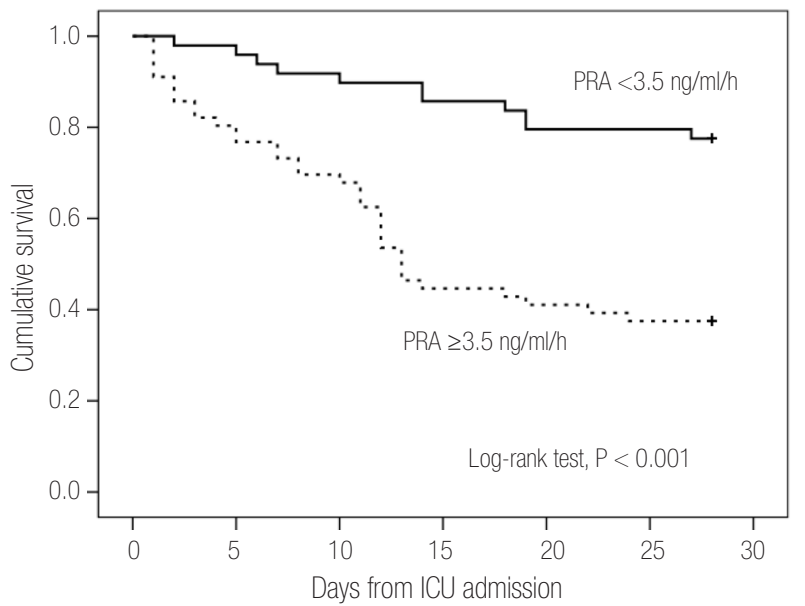

Figure 5. Kaplan-Meier survival curves for 28 days according to PRA. The cutoff value was the optimal cutoff limit that predicted 28 -day mortality (PRA $<3.5 \mathrm{ng} / \mathrm{ml} / \mathrm{h}$ or $\geq 3.5 \mathrm{ng} / \mathrm{ml} / \mathrm{h}$ ). PRA: plasma renin activity; ICU: intensive care unit.

Table 3. Univariate and multivariate Cox model for 28-day mortality in patients with septic shock

\begin{tabular}{|c|c|c|c|c|c|c|}
\hline \multirow{2}{*}{ Covariable } & \multicolumn{3}{|c|}{ Univariate analysis } & \multicolumn{3}{|c|}{ Multivariate analysis } \\
\hline & HR & $95 \% \mathrm{Cl}$ & P-value & HR & $95 \% \mathrm{Cl}$ & P-value \\
\hline APACHE II score & 1.073 & $1.028-1.121$ & 0.001 & & & \\
\hline SOFA score & 1.169 & $1.082-1.263$ & $<0.001$ & 1.112 & $1.011-1.224$ & 0.029 \\
\hline Previous cancer history & 3.140 & $1.591-6.197$ & 0.001 & 3.442 & $1.717-6.899$ & $<0.001$ \\
\hline CAOD history & 2.645 & $1.179-5.935$ & 0.018 & 2.989 & $1.263-7.075$ & 0.013 \\
\hline Steroid use within 7 days & 1.945 & $1.068-3.542$ & 0.030 & & & \\
\hline CRRT within 7 days & 2.290 & $1.265-4.147$ & 0.006 & 1.769 & $0.924-3.385$ & 0.085 \\
\hline Heart rate & 1.011 & $1.000-1.022$ & 0.048 & & & \\
\hline Net fluid balance at day 1 & 1.000 & $1.000-1.000$ & 0.011 & & & \\
\hline $\mathrm{PaO}_{2} / \mathrm{FlO}_{2}$ ratio & 0.998 & $0.995-1.001$ & 0.130 & & & \\
\hline $\mathrm{PRA} \geq 3.5 \mathrm{ng} / \mathrm{ml} / \mathrm{h}$ & 3.943 & $1.996-7.790$ & $<0.001$ & 3.245 & $1.596-6.597$ & 0.001 \\
\hline$P A C \geq 112 \mathrm{ng} / \mathrm{dl}$ & 2.642 & $1.466-4.760$ & 0.001 & & & \\
\hline
\end{tabular}

HR: hazard ratio; Cl: confidence interval; APACHE: Acute Physiology and Chronic Health Evaluation; SOFA: Sequential Organ Failure Assessment; CAOD: coronary artery obstructive disease; CRRT: continuous renal replacement therapy; PRA: plasma renin activity; PAC: plasma aldosterone concentration. 
last decade, new components of the RAAS have been found to be involved in many essential pathophysiological processes, such as development, inflammation, and remodeling $[10,11]$. Recently, the relevance between the potentially proinflammatory effects of angiotensin II and the pathogenesis of sepsis and acute lung injury has been of interest [12-14]. Blocking of a pro-renin receptor attenuates an inflammatory response in an animal model of sepsis using rat [15]. Many serum markers in the inflammatory cascade have been assessed in sepsis as potential indicators of infection [16]. In particular, the RAAS plays important roles in controlling blood pressure, microvascular regulation, and organ function, as well as in inflammatory responses. In our study, there was a positive linear correlation between PRA or PACs and the organ failure score (SOFA score) in septic shock patients. We initially expected that elevated PRA or PACs may also contribute to a stronger inflammatory response and may be a similarly useful prognostic indicator as serial CRP measurements in prediction of infection [17] and in monitoring treatment responses [18-20]. However, there was no linear correlation between PRA or PACs and CRP levels. Further studies are required to determine the role of PRA and PACs in the inflammatory response using other inflammatory markers.

This was the first study to elucidate the relationship between PRA and mortality in patients with septic shock. There have been no studies on the association between PRA and mortality in patients with septic shock. However, in animal experiments, there is evidence between RAAS activity and sepsis [11]. In some studies, hyperreninemic hypoaldosteronism has been identified as a potential prognostic indicator of septic shock-induced acute renal failure [8] and liver cirrhosis [21]. du Cheyron et al. [8] showed that hyperreninemic hypoaldosteronism might be related with acute kidney injury in patients with septic shock. In our study, $55.2 \%$ of patients with septic shock had hyperreninemic hypoaldosteronism. du Cheyron et al. [8] found hyperreninemic hypoaldosteronism in $48 \%$ of septic shock patients, which is similar to our study. However, we did not find any correlations between hyperreninemic hypoaldosteronism and any clinical outcome, such as renal failure, ventilator-free days, ICUfree days, and 28-day mortality (data not shown). Similar to our study, du Cheyron et al. [8] also found that patients with septic shock showed markedly elevated PRA levels, associated with volume depletion and catecholamine-induced stimulation of $\beta$-adrenergic receptors. In our study, the non-survivor group showed higher PRA and PACs than did the survivor group, despite a greater net fluid balance on day 1 . This finding suggests that patients with higher PRA and PACs need much more fluid administration for intravascular volume depletion than expected. In our data, PRA was consistently higher in non-survival group (Figure 2A). Therefore, mortality in septic shock patients may be relevant with prolonged plasma renin activation not merely hyperreninemic hypoaldosteronism defined as a fixed cutoff (PAC/PRA $<2$ ).

The effects of the RAAS are no longer considered to be limited to the circulatory system. This is because system components are also produced and activated in situ in other tissues, including the brain, blood vessels, adrenals, adipose tissue, kidney, and heart, acting through paracrine and autocrine mechanisms [22]. In particular, angiotensin II can promote cell growth and inflammation by enhancing expression of endothelium-derived adhesion molecules [23] and production of pro-inflammatory cytokines and chemokines [24]. Angiotensin II also has procoagulant activity [25], and can stimulate reactive oxygen species production [26]. This results in increased microvascular hydraulic permeability [27] and capillary leakage in severe sepsis. Doerschug et al. [7] showed that PRA was correlated with plasma concentrations of angiotensin II, microvascular dysregulation, and organ failure in patients with septic shock. Accordingly, longterm RAAS over-activation may be harmful in patients with severe sepsis and septic shock, regardless of hyperreninemic hypoaldosteronism. In our serial follow-up data (day 1, day 3, and day 7), consistently high PRA levels were observed in non-survivor groups. And we found the relation between high PRA level and mortality in septic shock in Cox regression model. Therefore 
we support a negative effect on survival in septic shock patients by long-term RAAS over-activation. Hirano et al. [15] showed that a (pro) renin receptor blocker significantly improved survival in rats with clinically relevant sepsis induced through cecal ligation and puncture. However, further human data on RAAS activity in sepsis are required. In a practical situation, it may be important to identify the appropriate time and subject to receive a RAAS antagonist because of the beneficial role of angiotensin II in maintaining vascular tone during septic shock. Our study showed that renin activity $\geq 3.5 \mathrm{ng} \mathrm{ml}^{-1} \mathrm{~h}^{-1}$ was significantly correlated with 28-day mortality in patients with septic shock. This finding can be used as the basis for selection of (pro) renin blocker candidates for future clinical studies. Interestingly, Vergaro et al. [28] showed that a cutoff value for PRA $\geq 2.3 \mathrm{ng} \mathrm{ml}^{-1} \mathrm{~h}^{-1}$ was the best predictor of cardiac mortality in patients with heart failure, which is similar to our finding. In future studies, cutoff values for PRA should be investigated in various diseases.

We are aware of some limitations of our research. First, this small, single-center, retrospective cohort study should not be generalized. Large-scale, multicenter, prospective validation studies are required to confirm these findings. Although this was a retrospective cohort study, we attempted to remove confounding factors from the data, such as prior use of angiotensin-converting enzyme inhibitors, angiotensin receptor blockers, aldosterone antagonists, and steroids, as well as the effect of terminal renal failure. Second, we did not perform adrenocorticotropic hormone stimulation tests to assess the adequacy of adrenal function. This is a major limitation, even though an adrenocorticotropic hormone stimulation test is usually not recommended in patients with septic shock [29]. In addition, no data about thyroid function test can affect the results of our study. Third, we did not examine plasma angiotensin II concentrations because angiotensin II are not correlated with SOFA score in the later course of sepsis [7]. Additionally, a previous study showed that angiotensin II activity is only correlated with organ failure only during initial treatment. However, we wished to evaluate PRA and PACs over the course of septic shock. Fourth, in this study, the ROC AUC of APACHE II and SOFA score were relatively low because it may be due to the difference in the timing of beginning of septic shock and the time of admission to the ICU. And elevated PRA levels cannot be generalized to the entire sepsis patients because our study was aimed only at patients with septic shock. These points required careful interpretation. Finally, we only assessed CRP as an inflammatory marker with PRA and PACs. We did not measure blood lactate levels, procalcitonin, or prothrombin time for inflammation or coagulation system. Other biomarkers may show different results.

In conclusion, based on our findings, elevated PRA might be a useful prognostic biomarker for risk stratification of patients with septic shock, and an indicator of 28-day mortality. Therefore, the results of our study support that PRA can be a potential therapeutic target. In the future, multicenter, large-scale studies on RAAS inhibition, such as PRA antagonists may be needed for septic shock treatment.

\section{ORCID}

$\begin{array}{ll}\text { Kyung Soo Chung } & \text { http://orcid.org/0000-0003-1604-8730 } \\ \text { Moo Suk Park } & \text { http://orcid.org/0000-0003-0820-7615 }\end{array}$

\section{Supplementary Materials}

The online-only Supplement data are available with this article online: https://doi.org/10.4266/kjccm.2017.00094.

\section{References}

1. Angus DC, Linde-Zwirble WT, Lidicker J, Clermont G, Carcillo J, Pinsky MR. Epidemiology of severe sepsis in the United States: analysis of incidence, outcome, and associated costs of care. Crit Care Med 2001;29:1303-10. 
2. Martin GS, Mannino DM, Eaton S, Moss M. The epidemiology of sepsis in the United States from 1979 through 2000. N Engl J Med 2003;348:1546-54.

3. Bone RC, Grodzin CJ, Balk RA. Sepsis: a new hypothesis for pathogenesis of the disease process. Chest 1997;112:235-43.

4. Marik PE, Zaloga GP. Adrenal insufficiency in the critically ill: a new look at an old problem. Chest 2002;122:1784-96.

5. Annane D, Sébille V, Troché G, Raphael JC, Gajdos P, Bellissant E. A 3-level prognostic classification in septic shock based on cortisol levels and cortisol response to corticotropin. JAMA 2000;283:1038-45.

6. Rothwell PM, Lawler PG. Prediction of outcome in intensive care patients using endocrine parameters. Crit Care Med 1995;23:78-83.

7. Doerschug KC, Delsing AS, Schmidt GA, Ashare A. Renin-angiotensin system activation correlates with microvascular dysfunction in a prospective cohort study of clinical sepsis. Crit Care 2010;14:R24.

8. du Cheyron D, Lesage A, Daubin C, Ramakers M, Charbonneau P. Hyperreninemic hypoaldosteronism: a possible etiological factor of septic shock-induced acute renal failure. Intensive Care Med 2003;29: 1703-9.

9. Levy MM, Fink MP, Marshall JC, Abraham E, Angus D, Cook D, et al. $2001 \mathrm{SCCM} / \mathrm{ESICM} / \mathrm{ACCP} /$ ATS/SIS International Sepsis Definitions Conference. Intensive Care Med 2003;29:530-8.

10. Cousin C, Bracquart D, Contrepas A, Nguyen G. Potential role of the (pro)renin receptor in cardiovascular and kidney diseases. J Nephrol 2010;23:508-13.

11. Salgado DR, Rocco JR, Silva E, Vincent JL. Modulation of the renin-angiotensin-aldosterone system in sepsis: a new therapeutic approach? Expert Opin Ther Targets 2010;14:11-20.

12. Imai Y, Kuba K, Rao S, Huan Y, Guo F, Guan B, et al. Angiotensin-converting enzyme 2 protects from severe acute lung failure. Nature 2005;436:112-6.

13. Hagiwara S, Iwasaka H, Hidaka S, Hasegawa A, Koga H, Noguchi T. Antagonist of the type-1 ANG II receptor prevents against LPS-induced septic shock in rats. Intensive Care Med 2009;35:1471-8.

14. Hagiwara S, Iwasaka H, Matumoto S, Hidaka S, Noguchi T. Effects of an angiotensin-converting enzyme inhibitor on the inflammatory response in in vivo and in vitro models. Crit Care Med 2009;37: 626-33.

15. Hirano Y, Takeuchi H, Suda K, Hagiwara T, Miyasho T, Kawamura Y, et al. (Pro)renin receptor blocker improves survival of rats with sepsis. J Surg Res 2014;186:269-77.

16. Pierrakos C, Vincent JL. Sepsis biomarkers: a review. Crit Care 2010;14:R15.

17. Póvoa P, Coelho L, Almeida E, Fernandes A, Mealha R, Moreira P, et al. Early identification of intensive care unit-acquired infections with daily monitoring of C-reactive protein: a prospective observational study. Crit Care 2006; 10:R63.

18. Póvoa P, Coelho L, Almeida E, Fernandes A, Mealha R, Moreira P, et al. C-reactive protein as a marker of ventilator-associated pneumonia resolution: a pilot study. Eur Respir J 2005;25:804-12.

19. Póvoa P, Coelho L, Almeida E, Fernandes A, Mealha $\mathrm{R}$, Moreira $\mathrm{P}$, et al. Pilot study evaluating C-reactive protein levels in the assessment of response to treatment of severe bloodstream infection. Clin Infect Dis 2005;40:1855-7.

20. Póvoa P, Teixeira-Pinto AM, Carneiro AH; Portuguese Community-Acquired Sepsis Study Group SACiUCI. C-reactive protein, an early marker of community-acquired sepsis resolution: a multicenter prospective observational study. Crit Care 2011;15:R169.

21. du Cheyron D, Bouchet B, Cauquelin B, Guillotin D, Ramakers M, Daubin C, et al. Hyperreninemic hypoaldosteronism syndrome, plasma concentrations of interleukin-6 and outcome in critically ill patients with liver cirrhosis. Intensive Care Med 2008;34:116-24.

22. Lavoie JL, Sigmund CD. Minireview: overview of the renin-angiotensin system--an endocrine and paracrine system. Endocrinology 2003;144:2179-83. 
23. Liu HQ, Wei XB, Sun R, Cai YW, Lou HY, Wang $\mathrm{JW}$, et al. Angiotensin II stimulates intercellular adhesion molecule-1 via an AT1 receptor/nuclear factor-kappaB pathway in brain microvascular endothelial cells. Life Sci 2006;78:1293-8.

24. Ruiz-Ortega M, Ruperez M, Lorenzo O, Esteban V, Blanco J, Mezzano S, et al. Angiotensin II regulates the synthesis of proinflammatory cytokines and chemokines in the kidney. Kidney Int Suppl 2002;(82): S12-22.

25. Chai SY, Fernando R, Peck G, Ye SY, Mendelsohn FA, Jenkins TA, et al. The angiotensin IV/AT4 receptor. Cell Mol Life Sci 2004;61:2728-37.

26. Higuchi S, Ohtsu H, Suzuki H, Shirai H, Frank GD, Eguchi S. Angiotensin II signal transduction through the AT1 receptor: novel insights into mechanisms and pathophysiology. Clin Sci (Lond) 2007;112:417-28.

27. Newton CR, Curran B, Victorino GP. Angiotensin II type 1 receptor activation increases microvascular permeability via a calcium dependent process. J Surg Res 2005;123:33-9.

28. Vergaro G, Emdin M, Iervasi A, Zyw L, Gabutti A, Poletti R, et al. Prognostic value of plasma renin activity in heart failure. Am J Cardiol 2011;108:246-51.

29. Dellinger RP, Levy MM, Rhodes A, Annane D, Gerlach H, Opal SM, et al. Surviving Sepsis Campaign: international guidelines for management of severe sepsis and septic shock, 2012. Intensive Care Med 2013;39:165-228. 